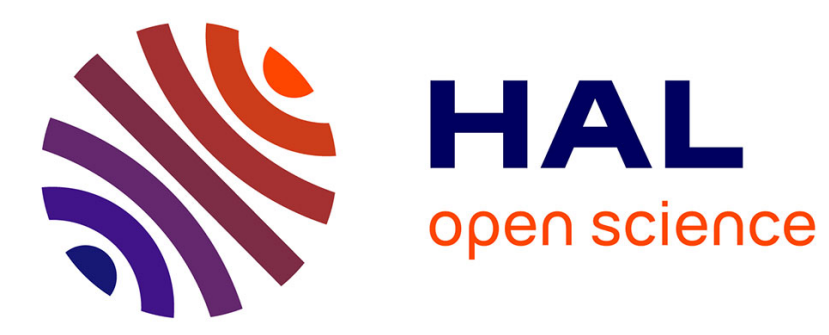

\title{
Evaluation of Cashew Nut Shell Liquid Derived Isocyanate Blocking Agents
}

Pietro Campaner, Yun Mi Kim, Chetan Tambe, Anbu Natesh

\section{To cite this version:}

Pietro Campaner, Yun Mi Kim, Chetan Tambe, Anbu Natesh. Evaluation of Cashew Nut Shell Liquid Derived Isocyanate Blocking Agents. International journal of advanced Science and Engineering, 2020, 7 (2), pp.1642-1651. 10.29294/IJASE.7.2.2020.1642-1651 . hal-03109767

\section{HAL Id: hal-03109767 https://hal.science/hal-03109767}

Submitted on 25 Jan 2021

HAL is a multi-disciplinary open access archive for the deposit and dissemination of scientific research documents, whether they are published or not. The documents may come from teaching and research institutions in France or abroad, or from public or private research centers.
L'archive ouverte pluridisciplinaire HAL, est destinée au dépôt et à la diffusion de documents scientifiques de niveau recherche, publiés ou non, émanant des établissements d'enseignement et de recherche français ou étrangers, des laboratoires publics ou privés. 


\title{
Evaluation of Cashew Nut Shell Liquid Derived Isocyanate Blocking Agents
}

\author{
Pietro Campaner ${ }^{1}$, Yun Mi Kim², Chetan Tambe², Anbu Natesh ${ }^{2 *}$ \\ ${ }^{1}$ AEP Polymers Srl, c/o AREA Science Park, SS 14, Km 163.5, Basovizza, Trieste, 34149, Italy \\ ${ }^{2}$ Cardolite Corporation, 140 Wharton Road, Bristol, PA 19007, Unites States of America (USA)
}

\begin{abstract}
Cardanol(3-pentadecenyl-phenol) is a well-known non-edible natural oil derived from Cashew Nutshell Liquid and represents a valid alternative to petro-based derivatives (e.g. nonylphenol) as a protective group (blocking agent) for isocyanates. In fact, once used in polyurethane prepolymers, this substance demonstrates various benefits including favorable deblocking conditions, lower viscosity, and excellent storage stability in comparison to commonly used phenolic compounds. One of the most known deblocking methods involves the exposure to elevated temperatures, typically around $150{ }^{\circ} \mathrm{C}-200^{\circ} \mathrm{C}$. However, not all substrates (e.g. plastics) and applications can tolerate such high temperatures, therefore the possibility to optimize the deblocking conditions can be a valuable tool to further expand the applicability of cardanol as a sustainable, eco-friendly polyurethane prepolymers' blocking agent. In this Paper, different approaches to tune deblocking conditions will be investigated, like the use of catalysts, deblocking agents (e.g. amines, polyols), and chemical modification of cardanol aromatic ring by nitration, to introduce electron withdrawing groups. Model cardanol-blocked substrates will be synthesized starting from commercially available isocyanates (both aromatic and aliphatic) and polymeric diols, subsequently characterized for their thermal behaviorby Different Scanning Calorimetry (DSC).
\end{abstract}

KEYWORDS:cardanol; nitration;isocyanates; deblocking temperature;Differential Scanning Calorimetry (DSC)

https://doi.org/10.29294/IJASE.7.2.2020.1642-1651

(c) 2020 Mahendrapublications.com, All rights reserved

\section{INTRODUCTION}

Cashew Nut Shell Liquid (CNSL), largely available in the entire sub-tropical area (Brazil, India, Vietnam, Ivory Coast, etc.), is a non-food chain industrial oil found in the honeycomb structure of the cashew nutshell (Anacardium Occidentale), typically considered a by-product of the cashew nut industry.

The main product isolated by vacuum distillation of CNSL under proper conditions is cardanol, anUSDA certified bio-based ( $>98 \%$ bio-content) alkenylphenolic product with an average number of two unsaturations on the $\mathrm{C}_{15}$ side-chain (Figure 1 ).<smiles>[R]c1cccc(O)c1</smiles>

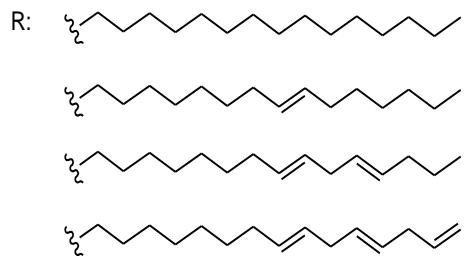

Figure 1: Cardanol structure

Cardanol represents an interesting and versatile monomer, as it contains three different functional groups (the aromatic ring, the hydroxyl group and the double bonds in the alkyl chain), that can be either selectively or simultaneously modified according to the expected features of final product.

Given its peculiar chemical structure, several chemical routes to cardanol-based derivatives have been reported in the literature, including epoxies, amine curing agents, surfactants, friction particles, phenolic resins [1] and benzoxazines [2]

For example, one of the most successful CNSL's applications are epoxy curing agents, a type of derivatives exhibiting good reactivity for fast and low temperature cure, strong adhesion even to damp or poorly prepared surfaces, excellent water resistance, corrosion protection and chemical resistance in epoxy formulations, all properties imparted by cardanol's peculiar chemical backbone.

All the average benefits described above have been also exploited in sectors like polyurethane systems, where cardanol has been described as a useful building block for polyols and derivatives suitable for $2 \mathrm{~K}$ PU applications [3], aiming, for example, to improve PU adhesives and coatings durability by imparting hydrophobicity and chemical resistance.In order to further confirm the versatility of cardanol and its$$
\text { groups (the aromatic ring the hydroxyl group and he }
$$

\section{*Corresponding Author:anatesh@cardolite.com}
Received: 11.10 .2020
Accepted: 20.10 .2020
Published on: 01.11.2020 
potential applicability in different sectors like $1 \mathrm{~K}$ PU systems, cardanol and cardanol derivatives have been already described in the literature [4,5]as possible isocyanate blocking agents, to protect terminal isocyanate groups from moisture absorption and subsequent degradation (Figure 2).

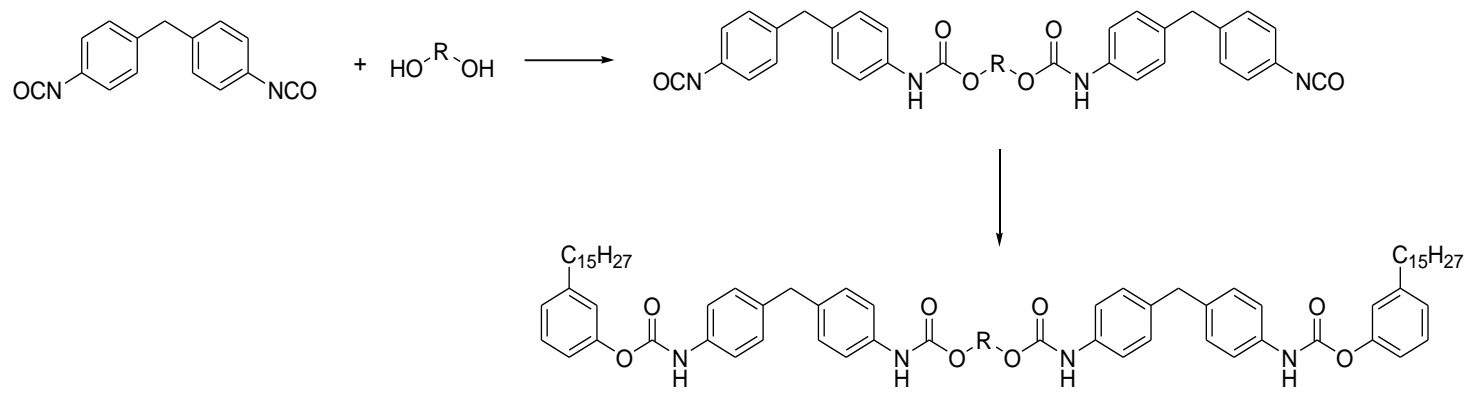

Figure 2: general reaction scheme for 4,4'-methylene diisocyanate (MDI) based prepolymer synthesis followed by blocking reaction with cardanol

The present work aims to further extend the number of examples of cardanol as blocking agent and explore formulations tools (selected among metal and amine catalysts, chain extenders like polyols and amines; chemical modifications like nitration) to tune its deblocking temperatureswhen used in combination with different type of isocyanates and prepolymers.

\section{EXPERIMENTAL}

\subsection{Materials}

High purity cardanol(indicated as "cardanol" in the rest of the text) and side chain hydrogenated cardanol were from Cardolite Corporationunder the trade names NX-2026 and NC-510, respectively, and used without any purification. Nitric acid, isopropanol, diisobutyl amine, hydrochloric acid $1 \mathrm{~N}$ methanolic solution, methyl-ethyl ketone, mono-chlorobenzene, 1,4-diazobicylco[2.2.2] octane, zinc acetylacetonate,dimethylethanolamine, phenol, nonylphenol, $\varepsilon$-caprolactamwere obtained by SigmaAldrich. Polymeric diol Voranol 2000L (polypropylene glycol MW 2000 Da) was supplied by DOW Chemicals. Chain extenders Isoter 801SA, Jeffamine D230, LITE 2002, isophoronediamine were supplied by COIM, Huntsman, Cardolite Corporation and Sigma-Aldrich, respectively. Aromatic isocyanates Ongronat 3050 (4,4'-methylene diisocyanate, MDI) and Desmodur T80 (Toluene diisocyanates,TDI) were supplied by Borsodchem and Covestro, respectively. Aliphatic isocyanates hexamethylene diisocyanates (HDI) and isophorone diisocyanate (IPDI) were both supplied by Vencorex. Catalysts potassium-octoate in diethylene glycol (DABC0 K15), tin dibutyl dilaurate(DABCO T12), dibutylbis(dodecylthio) stannane (DABCO T120), Triethylene diamine in dipropylene glycol (Dabco
33LV), N,N,N,-tris(3-dimethylaminopropyl)-amine (Polycat 9), 2-ethylhexanoic acid solution of triethylenediamine (DABCO 8154), tris-2,4,6dimethylaminomethyl phenol (Ancamine K54) were all supplied by EVONIK. Zinc-amine catalyst (K-KAT XK614), bismuth carboxylate catalyst (K-KAT XK-640), zinc catalyst in butanol (K-KAT XK-672) were all supplied by King Industries.

\subsection{Synthesis of nitro-pentadecyl-phenol}

Nitrated cardanol (nitro-pentadecyl-phenol) was prepared following standard nitration protocols already described in the literature and successfully applied to side chain hydrogenated cardanol, 3pentadecyl-phenol[6,7].In a typical procedure, sidechain hydrogenated cardanol 3-pentadecylphenol (302 $\mathrm{g}, 1 \mathrm{eq}, 1 \mathrm{~mol}$ ) is charged in a three-necked round bottom flask equipped with temperature control, mechanical stirrer and reflux condenser. Isopropanol $(350 \mathrm{ml})$ is then added andthe system stirred at room temperature till complete solubilization. Nitric acid $65 \%$ (116.8 g, $1.2 \mathrm{eq}$ ) is then added dropwise, keeping temperature at $25-30^{\circ} \mathrm{C}$. The solution is then left under vigorous stirring at room temperature for 4 hours, diluted with toluene and then washed with a saturated aqueous solution of sodium hydrogen carbonate till neutrality. The neutralizedorganic phase is thensubsequently washed with water and dried over anhydrous sodium sulfate. The solvent is removed under vacuum, recovering of a dark brown waxy solid (338 g, 97\%).

\subsection{Isocyanate content determination}

Isocyanate content has been determined accordingly to ASTM D2572 on a METTLER TOLEDO T50 automatic titrator. In a typical experiment, sample (about 1 gram

Pietro Campaner et al., 
weighed on an analytical scale) was dissolved in 25 $\mathrm{ml}$ of mono-chlorobenzene and $20 \mathrm{ml}$ of methyl ethyl ketone (MEK), added of $5 \mathrm{ml}$ of a $2 \mathrm{~N}$ di-isobutylamine solution in mono-chlorobenzene and titrated using $\mathrm{HCl}$ $1 \mathrm{~N}$ in methanol. A blank is measured under the same conditions.

\subsection{Preparation of prepolymers, blocked isocyanates and blocked prepolymers}

Prepolymers have been prepared starting from commercially available diols (polyester, polyether) according to the following procedure: to a weighed amount of isocyanate pre-heated at $50{ }^{\circ} \mathrm{C}$ and stirred under nitrogen atmosphere, the selected diol is added dropwise, keeping mixture temperature around 65-70 ${ }^{\circ} \mathrm{C}$. Once the addition is completed, the system is stirred under nitrogen atmosphere at the same temperature, monitoring prepolymer formation by isocyanate content titration.When the target NCO content is obtained, the prepolymer is then blocked by adding cardanol dropwise under stirring, keeping reaction temperature around $65-70{ }^{\circ} \mathrm{C}$ under nitrogen flush and monitoring NCO disappearance by titration. A similar procedure has been used to make isocyanate-cardanol adducts, still monitoring full NCO capping by automatic titration.

\subsection{Determination of deblocking temperature}

Deblocking temperatures have been determined by Differential Scanning Calorimetry on a METTLER TOLEDO DSC1 STAR System equipped with a HUBER TC45 thermostat, heating the sample $(10 \mathrm{mg}$ ) from 25 ${ }^{\circ} \mathrm{C}$ to $250{ }^{\circ} \mathrm{C}$ at $10{ }^{\circ} \mathrm{C} / \mathrm{min}$ under nitrogen. Initial deblocking temperature corresponds to a change in the baseline slope.

\section{RESULTS \& DISCUSSION}

The benefits of blocked isocyanates are well-known in various industries including coatings and adhesives [8]. Blocked isocyanate and blocked polyurethane prepolymer technology enable $1 \mathrm{~K}$ polyurethane systems with reduced free isocyanates and extended storage stability by minimizing moisture sensitivity of the system. Coating applications such as electrodeposition, electro-static spraying, powder coating, insulating wire coating, and coil coatings have extensively explored this technology because this approach provides a solution to minimize health concerns from free isocyanate exposure while allowing coatings to cure by heat. In the case of blocked prepolymers, they are used in $1 \mathrm{~K}$ and $2 \mathrm{~K}$ epoxy-amine adhesives, $1 \mathrm{~K}$ polyurethane hot-melts, pressure sensitive adhesives, and sealants.

Commonly used isocyanate blocking agents include phenol, nonylphenol (NP), methylethylketoxime
(MEKO), alcohols, $\varepsilon$-caprolactam, amides, imidazoles, and pyrazoles. The chemical structure of the blocking group has a major impact on the deblocking temperature and cure rate of the coating or adhesive, and also impact volatile content and final properties. Phenol or substituted phenols have been employed as isocyanate capping agents for many years, but recent health concerns over toxicity of these molecules offered opportunity to develop safer and affordable alternatives.

In order to have a first indication on cardanol behavior as NCO blocking agent, model isocyanatecardanol adducts have been prepared, using both aromatic (TDI) and aliphatic (IPDI) isocyanates at a cardanol/isocyanate stoichiometric ratio. The resulting adducts, labelled as CB-1 (cardanol-TDI adduct) and CB-2 (cardanol-IPDI adduct), have been then characterized for their deblocking temperatures.

Among all the analytical techniques (IR, TGA, UV-Vis, NMR, GC, GC-MS, titration, $\mathrm{CO}_{2}$ evolution, Gel Time, XRay Photoelectron Spectroscopy) applicable to estimate deblocking temperatures of blocked prepolymers [9], Differential Scanning Calorimetry (DSC) has been selected, due to easy and quick sample preparation, wide range of temperatures that can be screened and method sensitivity [10].

In a typical DSC experiment, cardanol blocked isocyanatesCB-1 and CB-2have been heated from $25^{\circ} \mathrm{C}$ to $250^{\circ} \mathrm{C}$ at $10^{\circ} \mathrm{C} / \mathrm{min}$ under nitrogen, accordingly to similar conditions already described in the literature [11].

These first data (Table 1) confirm that cardanolblocked substrates follow the same deblocking temperatures trend as typical blocking agents (Table 2, [12]), but also show that cardanol is characterized by relatively high deblocking temperatures that might limit its potential use as a versatile blocking agent in application where very fast cure profiles are required or where substrates to be treated are thermosensitive (e.g. plastics).

To address this topic and further investigate all the reaction pathways that blocked isocyanates could be subjected to (Figure 3, [13]), in addition to simple thermal deblocking, the impact of catalysts, chain extenders with different nucleophilicity (e.g. polyol and amines) or their combination has been investigated.

Using cardanol-isocyanate adducts CB-1 and CB-2as reference substrates, different catalysts selected among tertiary amines, alkanolamines, metals [14] have been added $(0.8 \% \mathrm{w} / \mathrm{w}$ with respect to the substrate), in order to check their potential capability to lower deblocking temperatures (Table 3).

\section{Pietro Campaner et al.,}


Table 1: deblocking temperatures of model cardanol-isocyanate adducts

\begin{tabular}{|c|c|}
\hline \multicolumn{2}{|c|}{ Deblocking temperature $\left({ }^{\circ} \mathbf{C}\right)$} \\
\hline CB-1 & CB-2 \\
\hline 118 & 140 \\
\hline
\end{tabular}

Table 2: typical average deblocking temperatures for different PU substrates

\begin{tabular}{|c|c|}
\hline Substrate & Average deblocking Temperature $\left({ }^{\circ} \mathbf{C}\right)$ \\
\hline Alkyl-NHCOO-Alkyl & 250 \\
\hline Aryl-NHCOO-Alkyl & 200 \\
\hline Alkyl-NHCOO-Aryl & 180 \\
\hline Aryl-NHCOO-Aryl & 120 \\
\hline
\end{tabular}
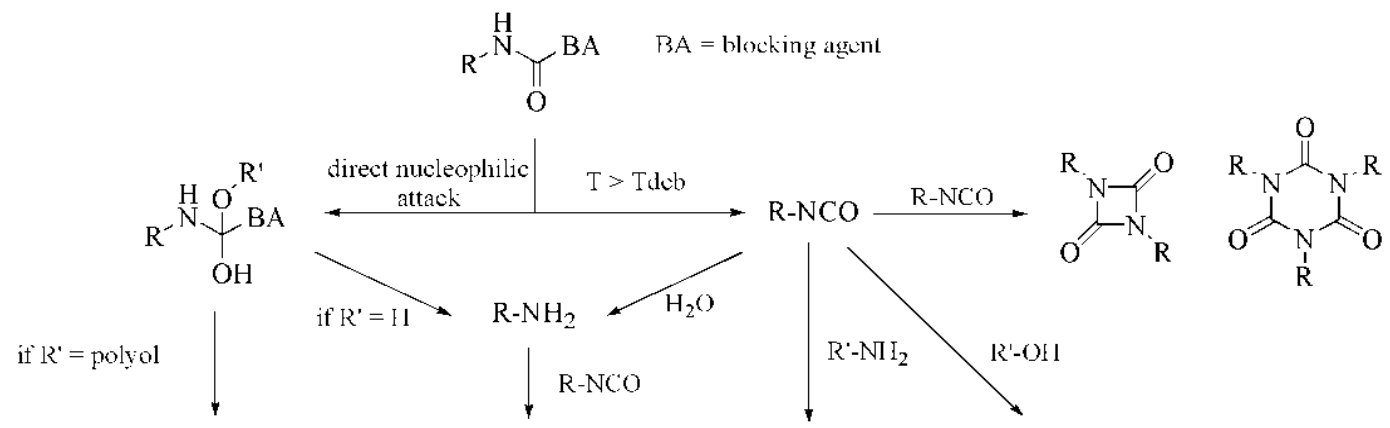

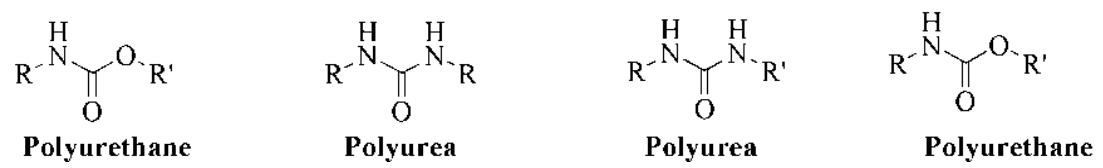

Figure 3: possible reactions of blocked isocyanates

Table 3: effect of catalystson deblocking temperatures of cardanol-isocyanate adducts.

\begin{tabular}{|l|c|c|}
\hline \multicolumn{1}{|c|}{ Catalyst } & \multicolumn{2}{c|}{ Deblocking temperature ( ${ }^{\circ}$ C) } \\
\cline { 2 - 3 } & CB-1 & CB-2 \\
\hline None & 118 & 140 \\
\hline 1,4-diazobicyclo[2.2.2]octane (DBO) & NO effect & 116 \\
\hline Acid blocked tertiary amine (DABC0 8154) & 82 & 117 \\
\hline Potassium-octoate in diethylene glycol (DABCO K15) & 92 & 82 \\
\hline Triethylenediamine in dipropyleneglycol (Tegoamin 33) & NO effect & 70 \\
\hline Zinc acetylacetonate (Tegokat 623) & 95 & 110 \\
\hline Tin Dibutyl dilaurate (DABCO T12) & 98 & 135 \\
\hline Zinc amine catalyst (K-KAT XK-614) & NO effect & 100 \\
\hline N,N-Dimethylethanolamine (Tegoamin DMEA) & 85 & NO effect \\
\hline tris-2,4,6-dimethylaminomethyl phenol (Ancamine K54) & NO effect & 92 \\
\hline
\end{tabular}

Pietro Campaner et al., 
Triethylenediamine (TEDA) in dipropyleneglycol and potassium-octoate in diethylene glycol show the highest effect/deblocking efficiency within the series, while other options are still suitable, but showing a slightly lower contribution. The high efficiency of these two catalyst can be explained considering both the nucleophilicity of the catalysts as well as the present of a polar solvent (dipropylene glycol and diethylene glycol) both catalysts are dispersed in $[15,16]$.

Even if suitable for a first screening, basic isocyanate-cardanol adducts $\mathbf{C B - 1}$ and $\mathbf{C B}-2$ are not truly representative of the polymeric substrates used in $1 \mathrm{~K} \mathrm{PU}$ applications.For this reason, the same catalysts have been tested on model cardanol-blocked prepolymers (Table 4).
In fact, four prepolymers have been prepared under the same process conditions, using polypropylene glycol (MW 2000) as starting polymeric diol and targeting a $4 \%$ free NCO content prior to full blocking with cardanol. The resulting cardanol blocked prepolymers, labelled as:
CBPU-1 (PPG $2000 / \mathrm{MDI} /$ cardanol), CBPU-2 (PPG $2000 / \mathrm{TDI} /$ cardanol), CBPU-3 (PPG 2000/HDI/cardanol) \& CBPU-4 (PPG $2000 /$ IPDI/cardanol),

have been then characterized for their deblocking temperatures under the same conditions as for adducts CB-1 and CB-2and the same catalyst load $(0.8 \% \mathrm{w} / \mathrm{w}$ with respect to the substrate).

Table 4: effect of catalystson deblocking temperatures of cardanol-blocked prepolymers

\begin{tabular}{|l|c|c|c|c|}
\hline \multirow{2}{*}{ Catalyst } & \multicolumn{3}{|c|}{ Deblocking temperature ( ${ }^{\circ}$ C) } \\
\cline { 2 - 5 } & CBPU-1 & CBPU-2 & CBPU-3 & CBPU-4 \\
\hline None & 165 & 120 & 186 & 178 \\
\hline 1,4-diazobicyclo[2.2.2] octane (DBO) & n.a. & n.a. & n.a. & 120 \\
\hline $\begin{array}{l}\text { Acid blocked tertiary amine } \\
\text { (DABCO 8154) }\end{array}$ & 98 & NO effect & 134 & N0 effect \\
\hline $\begin{array}{l}\text { Potassium-octoate in diethylene glycol (DABC0 } \\
\text { K15) }\end{array}$ & 60 & 105 & 80 & 76 \\
\hline $\begin{array}{l}\text { Triethylenediamine in dipropyleneglycol } \\
\text { (Tegoamin 33) }\end{array}$ & 86 & 80 & 120 & 160 \\
\hline Zinc acetylacetonate (Tegokat 623) & 96 & 105 & 140 & 90 \\
\hline Tin Dibutyl dilaurate (DABC0 T12) & n.a. & n.a. & 117 & 124 \\
\hline Zinc amine catalyst (K-KAT XK-614) & 112 & 110 & n.a. & 100 \\
\hline $\begin{array}{l}\text { tris-2,4,6-dimethylaminomethyl phenol } \\
\text { (Ancamine K54) }\end{array}$ & 120 & No effect & 150 & 104 \\
\hline
\end{tabular}

A similar trend as for basic adducts is observed as well, with potassium-octoate in diethylene glycol and TEDA showing the biggest effect, with a quite significant drop on prepolymers deriving from aromatic isocyanates (MDI or TDI).

With these promising results available, the study has then been further extended to slightly more complex systems, evaluating the use of chain extenders (as such or in combination with catalysts) characterized by different nucleophilicity (polyols and amines).

When a propoxylated sorbitol based polyol $\mathrm{COH}$ $300 \mathrm{mg} \mathrm{KOH} / \mathrm{g}$ ) is used as potential chain extender (at a stoichiometric level with respect to prepolymer equivalent weight), a reduction in deblocking temperature is observed, becoming even more significant when catalyst $(0.8 \% \mathrm{w} / \mathrm{w}$ with respect to overall substrate amount) are included in the blend (Table5).The evident effect of metal catalysts (e.g. dibutyltin dilaurate or potassium octoate) on deblocking temperatures can be explained with their capability to generate very nucleophilic metal alkoxylates in presence of polyols and polar solvents (as DEG, in the case of potassium octoate glycolic solution). The same mechanism is also described in the literature as a useful tool to depolymerize PU matrices like flexible foams (Figure 4) [17, 18].

As evident from the results shortlisted in Table 57, amine- and metal-type catalysts diluted with glycols (e.g. Tegoamin 33 and DABCO K15) show the overall best effect in reducing the deblocking temperatures of blocked prepolymers. However, their high nucleophilicity could potentially limit their applicability in $1 \mathrm{~K}$ systems, due to limited shelf-life (stability) of the blocked prepolymers.

\section{Pietro Campaner et al.,}


Table 5: effect of polyol and catalysts on deblocking temperatures of cardanol-blocked prepolymers

\begin{tabular}{|l|c|c|c|c|}
\hline \multirow{2}{*}{ Catalyst } & \multicolumn{4}{c|}{ Deblocking temperature ( ${ }^{\circ}$ C) } \\
\cline { 2 - 5 } & $\begin{array}{c}\text { CBPU-1 + } \\
\text { Polyol }\end{array}$ & $\begin{array}{c}\text { CBPU-2 + } \\
\text { Polyol }\end{array}$ & $\begin{array}{c}\text { CBPU-3 + } \\
\text { Polyol }\end{array}$ & $\begin{array}{c}\text { CBPU-4 + } \\
\text { Polyol }\end{array}$ \\
\hline None & 112 & 94 & 128 & 132 \\
\hline 1,4-diazobicyclo[2.2.2] octane (DB0) & 85 & n.a. & n.a. & n.a. \\
\hline $\begin{array}{l}\text { Potassium-octoate in diethyleneglycol (DABCO } \\
\text { K15) }\end{array}$ & 65 & 45 & 68 & 65 \\
\hline $\begin{array}{l}\text { Triethylenediamine in dipropyleneglycol } \\
\text { (Tegoamin 33) }\end{array}$ & 94 & 67 & 120 & 126 \\
\hline Tin Dibutyl dilaurate (DABCO T12) & 90 & 90 & 100 & 115 \\
\hline $\begin{array}{l}\text { tris-2,4,6-dimethylaminomethyl phenol } \\
\text { (Ancamine K54) }\end{array}$ & 94 & 78 & NO effect & NO effect \\
\hline
\end{tabular}<smiles>[Y][Si]([Y])(Br)Br</smiles>

$\mathrm{Bu}: \mathrm{C}_{4} \mathrm{II}_{9}$ $\mathrm{X}: \mathrm{CH}_{3}\left(\mathrm{CH}_{2}\right)_{10} \mathrm{COO}$

\section{IIO-R-OH}

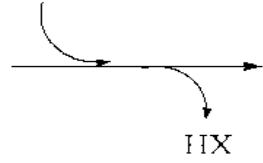<smiles>[Y][Sn](Br)(Br)O[R]O</smiles>

R'NIICOOR"<smiles>[R]ON1CC([R])([R18])O[R]([R])(Br)N1[R]</smiles>

Figure 4: proposed mechanism for PU depolymerization catalyzed by dibutyltin dilaurate

Table 6: MW variation (\%, determined by GPC) of cardanol-blocked PPG prepolymers in presence of very effective deblocking catalysts after storage at $50{ }^{\circ} \mathrm{C}$ for 10 days

\begin{tabular}{|l|c|c|c|c|}
\hline \multirow{2}{*}{ Catalyst } & \multicolumn{3}{c|}{ MW variation, \% (GPC) } \\
\cline { 2 - 5 } & CBPU-1 & CBPU-2 & CBPU-3 & CBPU-4 \\
\hline None & 7.2 & 2.3 & 7.9 & 5.3 \\
\hline $\begin{array}{l}\text { Potassium-octoate in } \\
\text { diethyleneglycol (DABC0 K15) }\end{array}$ & 339.1 & 515.4 & 130.6 & 521.3 \\
\hline $\begin{array}{l}\text { Triethylenediamine in } \\
\text { dipropyleneglycol (Tegoamin 33) }\end{array}$ & 137.9 & 438.9 & 16.0 & 15.8 \\
\hline
\end{tabular}

To confirm this assumption, the four model cardanol-blocked PPG-based prepolymers CBPU-1, CBPU-2, CBPU-3 and CBPU-4used for the study have been characterized for their molecular weight variation (by Gel Permeation Chromatography, GPC) after storage for 10 days at $50{ }^{\circ} \mathrm{C}$ (corresponding to approx. 3 months at room temperature), both as neat samples and as added with catalysts (Tegoamin 33; DABCO $\mathrm{K} 15 ; 0.8 \%$ load with respect to the substrate).

\section{Pietro Campaner et al.,}


If a significant amount of deblocking occurs over storage, then the resulting free prepolymer can crosslink (also favored by the presence of a catalyst), thus causing an increase in molecular weight or, in general, a significant difference in the MW distribution.Even if there could be potentially factors affecting the accuracy of molecular weight characterization based on hydrodynamic volume comparison between polymer standards (e.g. polystyrene) and polymer analytes having different chemistries, GPC represents quite a useful tool to screen several substrates by using small amounts of materials.

MW variations have been plotted in Table 6, showing a good stability for neat blocked prepolymers. When triethylenediamine in dipropyleneglycol (Tegoamin 33) is used, aliphatic isocyanates (HDI, IPDI) derived prepolymers show a limited variation in MW, while it becomes more evident for aromatic systems (MDI and TDI based). The effect is even worse when potassiumoctoate in diethylene glycol (DABCO K15) containing blends, almost all showing a complete gellation.

The same characterization has been extended in systems where the blocked prepolymers described above are blended with a polyol as chain extender (as described in Table 7), still using triethylenediamine in dipropyleneglycol (Tegoamin 33) and potassiumoctoate in diethylene glycol (DABCO K15) as catalysts.

In this case, the contribution of both chain extender and catalyst results in a higher MW variation (Table 7), that, even if less marked for HDI and IPDI systems, still highlights the limited applicability of very active catalysts (e.g. DABCO K15) in 1K PU systems as a tool to reduce deblocking temperatures without affecting blocked prepolymers shelf-life.

These results have therefore prompted the search for possible alternative catalysts, able to contribute to the reduction of the deblocking temperature (even if lower than for the former ones), but without affecting systems shelf-life. Considering the results obtained with aromatic isocyanates derived prepolymers, whose shelf-life is highly reduced by the presence of catalysts, specific attention has been given to the same model cardanol-blocked MDI- and TDI-based PPG prepolymers CBPU-1 and CBPU-2used in the rest of the study.

Table 7: MW variation (determined by GPC) of cardanol-blocked PPG prepolymers in presence of a propoxylated sorbitol polyol and Tegoamin 33 and DABCO K15 after storage at $50{ }^{\circ} \mathrm{C}$ for 10 days

\begin{tabular}{|l|c|c|c|c|}
\hline \multirow{2}{*}{ Catalyst } & \multicolumn{3}{c|}{ MW variation (\%) } \\
\cline { 2 - 5 } & $\begin{array}{c}\text { CBPU-1 } \\
\text { + Polyol }\end{array}$ & $\begin{array}{c}\text { CBPU-2 } \\
\text { + Polyol }\end{array}$ & $\begin{array}{c}\text { CBPU-3 } \\
\text { + Polyol }\end{array}$ & $\begin{array}{c}\text { CBPU-4 } \\
\text { + Polyol }\end{array}$ \\
\hline None & 32.5 & 200.7 & 8.4 & 16.8 \\
\hline $\begin{array}{l}\text { Potassium-octoate in diethyleneglycol } \\
\text { (DABCO K15) }\end{array}$ & 265.9 & 170.8 & 457.1 & 661.5 \\
\hline $\begin{array}{l}\text { Triethylenediamine in } \\
\text { dipropyleneglycol (Tegoamin 33) }\end{array}$ & 213.9 & 238.2 & 22.5 & 32.3 \\
\hline
\end{tabular}

The second set of catalysts (still selected among amine- and metal-based ones) show a lower effect on deblocking temperatures with respect to the most efficient ones belonging to the first series, but still providing a significant deblocking temperature reduction for all the model prepolymers, with or without the presence of a polyol as curing agent (Table 8). At the same time, the alternative catalysts show a general lower impact on shelf-life reduction (average lower increase in MW), especially in the case of MDIbased system CBPU-1, while with TDI-derivative CBPU-2 there's still an increase in molecular weight (even if lower than for Tegoamin 33 or DABCO K15).
Having confirmed the possibility of reducing deblocking temperature of cardanol-blocked prepolymers by polyols extension as well as the applicability of proper catalysts to further reduce the reaction temperature without affecting blocked prepolymers shelf-life, further experiments have been conducted to evaluate the efficiency of amines as chain extenders/curing agents characterized by higher nucleophilicity (Table 9) [19]. The four same reference model blocked prepolymers have been blended with amines, Jeffamine D230, LITE 2002, IPDA, respectively, at a stoichiometric level using the amine's AHEW (amine hydrogen equivalent weight) with respect to the prepolymer equivalent weight.

Pietro Campaner et al., 
Table 8: alternative catalysts' effect on deblocking temperatures and MW (determined by GPC)of cardanolblocked prepolymers

\begin{tabular}{|l|c|c|c|c|c|c|c|c|}
\hline \multirow{2}{*}{ Catalyst } & \multicolumn{5}{|c|}{ Deblocking temperature (') } & \multicolumn{3}{c|}{ MW variation (\%) } \\
\cline { 2 - 10 } & CBPU-1 & CBPU-2 & $\begin{array}{c}\text { CBPU-1 + } \\
\text { Polyol }\end{array}$ & $\begin{array}{c}\text { CBPU-2 + } \\
\text { Polyol }\end{array}$ & $\begin{array}{c}\text { CBPU- } \\
\mathbf{1}\end{array}$ & $\begin{array}{c}\text { CBPU-2 } \\
\text { CBPU-1 + }\end{array}$ & $\begin{array}{c}\text { CBPU- } \\
\text { Polyol + } \\
\text { Polyol }\end{array}$ \\
\hline None & 165 & 120 & 112 & 94 & 7.2 & 2.3 & 32.5 & 200.7 \\
\hline $\begin{array}{l}\text { N,N,N,-tris(3- } \\
\text { dimethylaminopropyl)- } \\
\text { amine (Polycat 9) }\end{array}$ & 91 & 102 & 95 & 74 & 85.2 & 574.4 & 186.2 & 352.0 \\
\hline $\begin{array}{l}\text { Stannane, } \\
\text { dibutylbis(dodecylthio) } \\
\text { (DABCO T120) }\end{array}$ & 75 & 80 & 90 & 85 & 9.4 & 93.3 & 141.2 & 310.9 \\
\hline $\begin{array}{l}\text { Bismuth carboxylate } \\
\text { catalyst (K-KAT XK- } \\
\text { 640) }\end{array}$ & 72 & 83 & 102 & 81 & 6.5 & 61.9 & 179.5 & 509.5 \\
\hline $\begin{array}{l}\text { Organometallic complex } \\
\text { catalyst (K-KAT XK- } \\
\text { 672) }\end{array}$ & 92 & 102 & 102 & 94 & 0.3 & 12.8 & 64.2 & 137.5 \\
\hline
\end{tabular}

Table 9: effect of amine chain extenders on deblocking temperatures of cardanol-blocked prepolymers

\begin{tabular}{|l|c|c|c|c|}
\hline \multirow{2}{*}{\multicolumn{1}{c|}{ Amine }} & \multicolumn{3}{c|}{ Deblocking temperature $\left({ }^{\circ} \mathbf{C}\right.$ ) } \\
\cline { 2 - 6 } & $\begin{array}{c}\text { CBPU-1 } \\
+ \text { Amine }\end{array}$ & $\begin{array}{c}\text { CBPU-2 } \\
+ \text { Amine }\end{array}$ & $\begin{array}{c}\text { CBPU-3 } \\
+ \text { Amine }\end{array}$ & $\begin{array}{c}\text { CBPU-4 + } \\
\text { Amine }\end{array}$ \\
\hline None & 165 & 120 & 186 & 178 \\
\hline Polyetheramine (Jeffamine D230) & 45 & 27 & 90 & 70 \\
\hline CNSL-based phenalkamine (LITE 2002) & 42 & 27 & 88 & 88 \\
\hline Isophoronediamine (IPDA) & 33 & 1 & 60 & 60 \\
\hline
\end{tabular}

Among the three amines tested as chain extenders (isophoronediame; polyetheramine; CNSLphenalkamine), the amine characterized by the lowest molecular weight shows the highest effect on deblocking temperature, probably due to its lower steric hindrance and the subsequent easier access to reactive groups.

The addition of catalysts in amine-type chain extenders can be a possible way to further reduce their deblocking temperatures, if necessary.

All these results confirm the effective applicability of cardanol as a versatile NCO-blocking agent suitable for applications ranging from coatings to adhesives to outdoor applications to epoxy-PU hybrid matrices [20].Depending on specific type of systems (1K or $2 \mathrm{~K}$ ), catalysts or chain extenders can be blended into cardanol blocked isocyanates-derived adducts, properly tuning their level and nature in order to have good balance between reactivity and formulation stability over time.

As an alternative approach to the use of catalysts, chain extenders or their combination, the chemical modification of cardanol has been also investigated as a possible tool to reduce deblocking temperatures of cardanol-blocked isocyanates.In particular, the introduction of an electron withdrawing group (EWG) on the aromatic ring has been considered a possible route to improve the lability of urethane bonds deriving from the reaction of a phenoxy and an isocyanate group. A perfect example of EWG is the nitro-group.

Since cardanol side chain double bonds are prone to crosslinking in presence of acids [21], generating high molecular weight species, side chain hydrogenated cardanol (3-penta-decyl-phenol) has been used as substrate, in order to prevent any side reaction during the nitration step (Figure 5).

\section{Pietro Campaner et al.,}




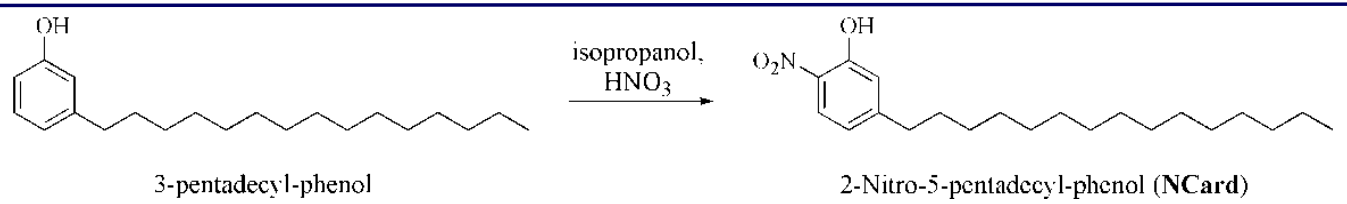

Figure 5: reaction scheme to convert 3-pentadecyl-phenolto 2-Nitro-5-pentadecyl-phenol (NC)

Once recovered, 2-nitro-5-pentadecyl-phenol NC was used as isocyanate blocking agent, following the same approach andreaction conditions previously described for the preparation of cardanol-isocyanate adducts CB1 and CB-2.

NC was reacted with both aromatic (MDI, TDI) and aliphatic (HDI, IPDI) diisocyanates at stoichiometric ratio, recovering four adducts named NCB-1 (NC/MDI), NCB-2 (NC/TDI), NCB-3 (NC/HDI) and NCB-4 (NC/IPDI). All the resulting derivatives were then characterized for their deblocking temperatures by DSC, scanning from $25{ }^{\circ} \mathrm{C}$ to $250{ }^{\circ} \mathrm{C}$ at $10{ }^{\circ} \mathrm{C} / \mathrm{min}$ rate under nitrogen.

As evident from the results reported in Table 10, all the adducts show lower deblocking temperatures than the ones obtained by reacting neat cardanol with the same diisocyanates, confirming the contribution of the nitro-group in reducing the thermal stability of the urethane bond.
To further extend the study and confirm the effect of the EWG on deblocking temperatures, model prepolymers have been prepared as well, still using polypropylene glycol MW 2000 as starting polymeric diol, MDI as NCO source and targeting a $4 \%$ free NCO content prior to full blocking. In this case, other reference blocking agents, selected among MEKO, $\varepsilon$ caprolactam and 3-pentadecylphenol have been have been tested as well, in order to have a direct comparison.

Blocked prepolymers MBPU (PPG 2000/MDI/MEKO), CaBPU (PPG $2000 / \mathrm{MDI} / \varepsilon$-caprolactam), hCBPU (PPG $2000 / \mathrm{MDI} / 3$-pentadecylphenol) and NCBPU (PPG $\left.{ }_{2000} / \mathrm{MDI} / \mathrm{NC}\right)$ were then tested by DSC to determine their deblocking temperatures and compared to CBPU-1 ( $\mathrm{PPG}_{2000} / \mathrm{MDI} /$ cardanol).

Table 10: Deblocking temperatures of 2-Nitro-5-pentadecyl-phenol (NC)-isocyanate adducts

\begin{tabular}{|c|c|c|}
\hline Substrate & Isocyanate type & Deblocking Temperature $\left({ }^{\circ} \mathbf{C}\right)$ \\
\hline NCB-1 & TDI & 78 \\
\hline NCB-2 & MDI & 82 \\
\hline NCB-3 & HDI & 89 \\
\hline NCB-4 & IPDI & 75 \\
\hline
\end{tabular}

Table 11: deblocking temperatures of a PPG2000/MDI blocked with different blocking agents

\begin{tabular}{|c|c|c|}
\hline Substrate & Blocking agent & Deblocking T ( $\left.{ }^{\circ} \mathbf{C}\right)$ \\
\hline CBPU-1 & cardanol & 165 \\
\hline MBPU & MEKO & 98 \\
\hline CaBPU & E-caprolactam & 120 \\
\hline hCBPU & 3-pentadecylphenol & 125 \\
\hline NCBPU & 2-nitro-5-pentadecylphenol (NC) & 85 \\
\hline
\end{tabular}

The same behavior (Table 11) has been observed for the NC-blocked prepolymer, showing a thermal stability comparable to MEKO-based and lower than cardanol, $\varepsilon$-caprolactam and 3-pentadecylphenol blocked prepolymers, thus confirming the positive effect of a nitro-group as a suitable tool to reduce deblocking temperatures, without necessarily using a catalyst or a nucleophile, as in the case of unmodified cardanol.

\section{CONCLUSIONS}

Cashew nutshell liquid (CNSL), a non-food chain, biorenewable alkenyl-aromatic, offers unique chemical features that can be successfully used in polyurethane

Pietro Campaner et al., 
applications. Its high pure derivative cardanol can be successfully used in $1 \mathrm{~K}$ systems as isocyanate blocking agent, representing an efficient alternative to petrobased phenol and nonylphenol.

By properly selecting suitable conditions (use of catalyst, chain extenders or their combinations, chemical modifications), cardanol deblocking temperatures can be tuned, offering to Formulators a valid and versatile chemical tool.

\section{REFERENCES}

[1] Parambath, A.,2017. Cashew Nut Shell Liquid: a Goldfield for Functional Materials, Springer International Publishing AG.

[2] Minigher, A., Benedetti, E., De Giacomo, O., Campaner, P., Aroulmoji, V., 2009, Synthesis and characterization of novel cardanol based benzoxazines. Natural product communications, 4 (4), 521.

[3] Desroches, M., Escouvois, M., Auvergne, R., Caillol, S., Boutevin, B., 2013. From Vegetable Oils to Polyurethanes: Synthetic Routes to Polyols and Main Industrial Products. Polymer Reviews, 52(1), 38.

[4] Nasar, A. S., Shrinivas, V.; Shanmugam, T., Raghavan, A., 2004. Synthesis and deblocking of cardanol- and anacardate-blocked toluene diisocyanates. Journal of Polymer Science: Part A: Polymer Chemistry, 42, 4047.

[5] Kim, Y. K., Natesh, A., Campaner, P., 2019. Cardanol - An Eco-friendly Isocyanate Blocking Agent. Coatings World -Technical Paper

[6] Wasserman, D., Dawson, C. R., 1950. Cashew Nut Shell Liquid. VIII. A proof of structure of the mono-nitro and mono-amino derivatives of 3pentadecylphenol (Hydrocardanol). Journal of the American Chemical Society, 72(11), 4994.

[7] Attanasi, O. A., Berretta, S., Fiani, C., Filippone, P., Mele, G., Saladino, R., 2006. Synthesis and reactions of nitro derivatives of hydrogenated cardanol. Tetrahedron, 62, 6113.

[8] Raquez, J. M.,Deleglise, M., Lacrampe, M. F.,Krawczak, P.,2010. Thermosetting (bio)materials derived from renewable resources: A critical review. Progress in Polymer Science, 35(4), 487.

[9] Lubi, M. C., Thachil, E. T.,2000. Cashew nut shell liquid (CNSL) - a versatile monomer for polymer synthesis. Designed Monomers and Polymers, $3(2), 123$.
[10] Bhunia, H. P., Nando, G. B., Chakia, T. K., Basak, A., Lenka, S., Nayak, P. L., 1999. Synthesis and characterization of polymers from cashew nutshell liquid (CNSL), a renewable resource II. Synthesis of polyurethanes. European Polymer Journal, 35(8), 1381.

[11] Mythili, C.V.,Retna, A. M.,Gopalakrishnan, S.,2004. Synthesis, mechanical, thermal and chemical properties of polyurethanes based on cardanol. Bulletin of Materials Science, 27(3), 235.

[12] Ionescu, M., Wan, X.,Bilic, N.,Petrovic, Z. S.,2012. Polyols and Rigid Polyurethanes from Cashew Nut Shell Liquid. Journal of Polymers and Environment. 20(3), 647

[13] Wicks, D. A., Wicks, Jr., Z. W.,2001. Blocked Isocyanates III: Part B: Uses and applications of blocked isocyanates. Progress in Organic Coatings, 41(1-3), 1.

[14] Wicks, D.A., Wicks, Jr., Z. W.,1999. Blocked isocyanates III: Part A. Mechanisms and chemistry. Prog. Org. Coatings, 36(3), 148.

[15] Mohanty, S., Krishnamurti, N., 1998. Synthesis and thermal deblocking of blocked diisocyanates adducts. European Polymer Journal, 34(1), 77.

[16] Duncan, J. S., Elmer, O. C.,1972. Composition for lowering the release temperature of phenol- and lower alkyl substituted phenol-blocked isocyanates. US3668186.

[17] Rolph, M. S.,Markowska, A. L. J.,Warriner, C. N., O'Reilly, R. K.,2016. Blocked isocyanates: from analytical and experimental considerations to non-polyurethane applications. Polymer Chemistry, 7, 7351

[18] Molero, C., de Lucas, A., Rodriguez, J. F., 2009. Activities of octoate salts as novel catalysts for the transesterification of flexible polyurethane foams with diethylene glycol. Polymer Degradation and Stability, 94(4), 533.

[19] Petrak, S., Shadurka, V., Binder, W. H., 2009. Cleavage of blocked isocyanates within aminotype resins: influence of metal catalysis on reaction pathways in model systems. Prog. Org. Coatings, 66(3), 296.

[20] Lee, J. M.,Subramani, S., Lee, Y. S.,Kim, J. H.,2005. Thermal decomposition behavior of blocked diisocyanates derived from mixture of blocking agents. Macromolecular Research, 13(5), 427.

[21] Manjula, S., Kumar, V. G., Pillai, C. K. S., 1992. Kinetics and mechanism of oligomerization of cardanol using acid catalysts. Journal of Applied Polymer Science, 45, 309.

All @ 2020 are reserved by International Journal of Advanced Science and Engineering. This Journal is licensed under a Creative Commons Attribution-Non Commercial-ShareAlike 3.0 Unported License.

Pietro Campaner et al., 